\title{
Structural Analysis of Xanthan GUM-FE (III) Capsules
}

\section{Elena Vázquez \\ Universidad Nacional de San Luis, PROICO 2-1612. Instituto de Tecnología Química-CONICET, Argentina}

\section{Sofía Piguillem}

Universidad Nacional de San Luis, PROICO 2-1612. Instituto de Tecnología Química-CONICET, Argentina

\section{Santiago Rubio}

Universidad Nacional de San Luis, PROICO 2-1612. Instituto de Tecnología Química-CONICET, Argentina

\section{Jorge Díaz}

Universidad Nacional de San Luis, PROICO 2-1612. Instituto de Tecnología Química-CONICET, Argentina

\section{Hector Baldoni}

Instituto de Matemática Aplicada de San Luis (IMASL), Área de Química General e Inorgánica, Facultad de Química, Bioquímica y Farmacia, Chacabuco y Pedernera, Universidad Nacional de San Luis, San Luis 5700, Argentina

\section{Enrique Vega}

Universidad Nacional de San Luis, PROICO 2-1612. Instituto de Tecnología Química-CONICET, Argentina

\section{Martin Masuelli (Corresponding Author)}

Laboratorio de Investigación y Servicios de Química Física (LISeQF-UNSL). Instituto de Física Aplicada-CONICET y FQByF-Universidad Nacional de San Luis, Ejercito de los Andes 950, ZC: 5700, San Luis, Argentina

Email: masuellimartin94@gmail.com

\begin{abstract}
In this work, the formation of capsules in xanthan gum and complexing solutions of Fe III is structurally evaluated. These capsules have a spheroid shape that, when dried, collapse into disc shapes. These spheroids are made up of microspheres that partially explain this collapse. The backscattered SEM image shows areas rich in Fe and others poorer in this metal, the EDX analysis confirms this. FTIR chromatograms show a clear shift at approximately $1620 \mathrm{~cm}-1 \mathrm{due}$ to the formation of the xanthan gum-Fe III complex. This work also proposes a structure, theoretically demonstrated, between xanthan gum and Fe III, which can explain what the biopolymeric structure bending procedure is like due to the presence of Fe III, a model called TransbiHook.
\end{abstract}

Keywords: Xanthan gum; Xanthan gum-fe III; Complex; Capsules; TransbiHook.

\section{Introduction}

Gums are compounds with molecules of a high-molecular weight, high solubility in water and which can produce gels or highly viscous solutions at low concentrations, this term is employed in the industry to refer to plant and microbial polysaccharides and their derivatives [1]. They have a variety of structural and functional properties, which are determined by their chemical composition, various molecular bonds and groupings, molar mass and its distribution. Virtually all of them are non-toxic and obtained at low cost in large quantities, which determines their importance for industrial processes [2-4].

Xanthan gum is a hetero-polysaccharide produced via microbial fermentation of the microorganism Xanthomonas campestris [5]. The primary unit of Xanthan gum (Figure 1) consists of a cellulosic backbone composed of two $\mathrm{D}^{-}$-glucose units (1-4) $\beta$-linked to a side-chain of ${ }_{\mathrm{D}^{-}}$-mannose and ${ }_{\mathrm{D}^{-}}$-glucuronic acid units at a ratio of $2: 1$, respectively [6]. D-Mannose, which is connected to the main backbone, is attached to an acetyl group at O6,

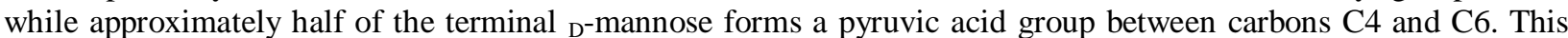
side-chain is found at the $\mathrm{O} 3$ atom of each alternate glucose unit on the backbone. Due to the presence of carboxylic groups in its structure, xanthan gum exhibits a net negative charge and can form complexes with cationic polymers [7]. In the last decade, the demand for xanthan gum, in industry, has been increasing at about 5-10\% per annum [8]. It is used in a broad variety of industries, including cosmetics, agriculture, food, textiles and oil [9, 10]. This is due to its safety (non-toxic), desirable rheological properties, high stability over a wide range of $\mathrm{pH}$ and temperature, together with its high resistance against enzymatic degradation $[11,12]$. 
Figure-1. Schematic chemical structure of the building units of xanthan gum [6].

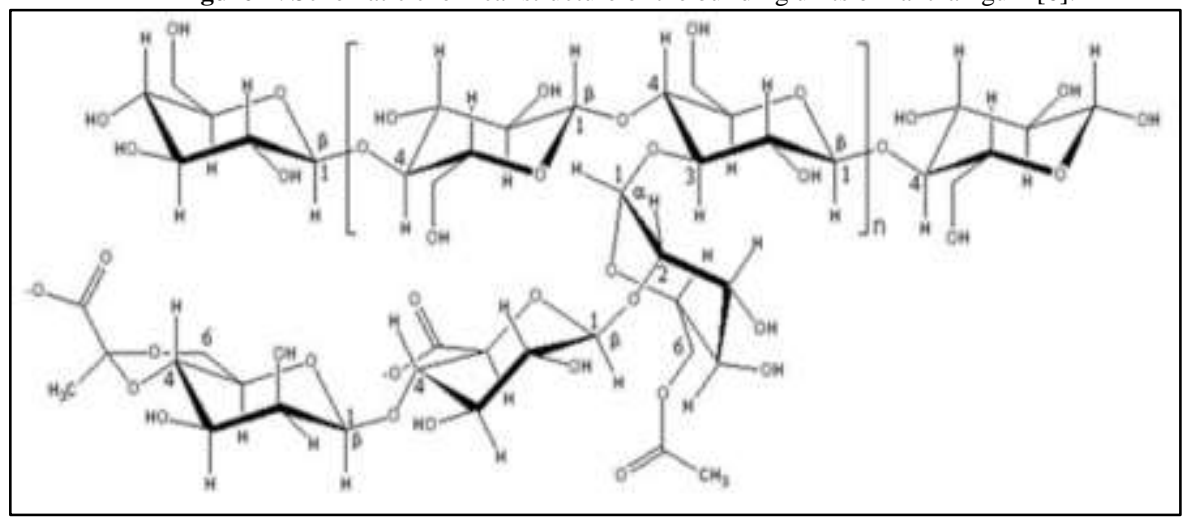

Most solutions of polysaccharides show, when heated, a decrease in viscosity, while solutions of xanthan gum in deionized water increase their viscosity after the initial decrease in viscosity. This behavior of xanthan gum suggests that a change in conformation is taking place [13]. The technique of optical rotation can be used to investigate changes in conformation, and the measurement of the optical rotation of the salt-free xanthan gum solution has shown that an increase in viscosity corresponds exactly to a decrease in optical rotation. This is consistent with the unwinding of an ordered conformation such as a helix to transform into a random spiral with a consequent increase in effective hydrodynamic volume and, therefore, in viscosity. The structural rigidity of the macromolecule produces several functional properties, such as its high viscosity in a wide range of concentrations, its solutions are stable over a wide range of $\mathrm{pH}$, salt concentration and temperatures, it is soluble in cold and hot it has good resistance to the processes of freezing and thawing [13-18]. The xanthan gum imparts a high viscosity (at rest) with small concentrations of the order of $1 \%$, and also presents a very marked pseudoplastic behavior. This characteristic makes it ideal to stabilize and give viscosity to products that must have a behavior similar to a gel at rest (when they are on the food) [19-21]. Its $\mathrm{pH}$ independence, even up to $\mathrm{pH} 2$, makes it possible to use it for very acidic foods, such as salad sauces. As a thickener and stabilizer, it has a high viscosity at low concentrations and is stable in the presence of salt, acids and elevated temperatures, as well as being stable against $\mathrm{pH}$, giving good stability to the suspensions or emulsions it forms [22]. It is not capable, this gum, by itself of forming gels, but of conferring to the foods to which a high viscosity is added using relatively low concentrations of substance, it is extremely resistant to enzymatic degradation, being stable in a wide range of temperature, $\mathrm{pH}$ and in high concentrations of alcohol, making it suitable for an exceptional range of uses and applications [23, 24]. One of the most extended approach to obtain capsules is the ionotropic gelation method, in which cations form insoluble associates with carbohydrate chains resulting in the so-called "egg-box" complexes [25, 26]. Alginate, majorly associated to calcium cations, has been largely used to encapsulate products [27-29], a similar case is pectin [30,31], chitosan [32, 33], and mix of these [34, 35].

Little is known about polysaccharide - metal complexes and impact of coordination to metal ions upon properties of those hydrocolloids [36, 37]. Recent papers were published on metal complexes of starches [38-41], amylose and amylopectins [42], cellulose [43], and three carrageenans [44-46]. In our former studies [42] anionic potato amylopectin and, in general ligation of metal atoms with potato starch was described. The anionic phosphate and the hydroxyl groups which participated in ligation provided formation of clathrates with water molecules trapped therein. Similarly, $\kappa-$, $1-$ and $\lambda$ - carrageenans formed clathrates with selected central metal atoms in corresponding their complexes. Carboxylic groups in the side chain provide anionic properties of the gum. The macromolecule forms a five-fold helical structure. Low salt concentration and elevated temperature favored a disorder of this structure whereas a higher salt concentration stabilized the ordered conformation.

It seemed likely, that the formation of the Werner-type metal complexes of the xanthan gum macro-ligand with central metal atom would additionally increase the water-holding ability of that polysaccharide and additionally stabilized the macroligand and water trapped in it.

To test this concept, xanthan gum complexes were synthesized with Fe (III), theoretical, structural, thermal and spectroscopic studies were performed.

\section{Experimental}

\subsection{Capsules Synthesis and Optic Analysis}

The xanthan gum (Xan) used in this study (Parafarm, Lot 000509) was spectroscopically characterized in order to determine its degree of purity [47]. As a complexing agent, $\mathrm{FeCl}_{3} 6 \mathrm{H}_{2} \mathrm{O}$ (Biopack) was used.

The processes of formation of the microspheres were carried out working in batch systems, placing in contact xanthan gum solution using syringe and drop by drop is added on complexing agent solution with continuous stirring at $300 \mathrm{rpm}$. Then, the spheres are removed by filtration and washed successively with distilled water until the solution is clear. The optimal concentrations of both reagents were determined, which allowed homogeneous particles to be obtained in terms of size and shape: Xan at $1 \%$ wt. and $\mathrm{FeCl}_{3} 0.5 \%$ wt.

The obtained capsules were photographed with Olympus LG-PS2 with camera Infinity 1 Lumintera and their approximate size was evaluated with a Vernier caliber. Likewise, the effect on the consolidation time of the capsule in contact with the Fe(III) solution was determined. 


\subsection{SEM-EDAX}

Morphology of capsules was observed using a scanning electron microscope (SEM) LEO 1450VP, and energy dispersion X-ray analysis was carried out using an EDS Genesis 2000 (EDAX). For the SEM morphological surface analysis, samples were prepared by immersion in liquid nitrogen and afterward coated with gold. They were observed under high vacuum and EDAX spectrums were obtained applying an acceleration voltage of $120 \mathrm{kV}$.

\subsection{Ftir Spectroscopy}

FTIR spectra were determined using an FTIR Varian 640 Spectrometer using ATR mode. The samples were dried at $60{ }^{\circ} \mathrm{C}$ for $48 \mathrm{~h}$ before performing the measurement. The obtained spectrum had a resolution of $4 \mathrm{~cm}^{-1}$ and consisted of approximately 3500 points with an integration times of $60 \mathrm{~s}(1 \mathrm{~s}$ per scan). Spectra were scanned between 4000 and $500 \mathrm{~cm}^{-1}$ at ambient temperature. The number of scans for each sample was 64 .

\subsection{Thermal Analysis. TGA and DSC}

Thermogravimetric analysis (TGA) was performed to estimate the thermal stability of the samples. TGA measurements were recorded on TG 2950 analyzers (TA Instruments, Inc., New Castle, USA), respectively. The operating conditions were as follows: (a) heating rate: $10^{\circ} \mathrm{min}^{-1}$ and, (b) atmosphere: static air or dynamic $\mathrm{N}_{2}$ ( $99.99 \%$, flow rate $50 \mathrm{~mL} / \mathrm{min}$, microfiltrate). The thermogravimetric temperature axes were calibrated with indium (99.99\%, melting point of $\left.156.60{ }^{\circ} \mathrm{C}\right)$ and the Curie point of $\mathrm{Ni}\left(353{ }^{\circ} \mathrm{C}\right)$, respectively. Empty aluminum pans $(40$ $\mathrm{mL}$ ) were used as references. Polysaccharide samples of about $8 \mathrm{mg}$ were employed.

\subsection{X-Ray Diffraction}

$\mathrm{X}$-Ray diffractions patterns were carried out using an equipment Rigaku model D-Max III C, lamp of Cu K and filter of Nickel. The $2 \theta$ operational range was from $0^{\circ}$ to $30^{\circ}$. The d-spacing were determined with the Bragg's equation.

\subsection{Structure Simulation}

The experimental results allowed to perform electronic calculations DFT-D at level BP98 / LANL2TZ: 6-311 + $\mathrm{G}(\mathrm{d}, \mathrm{p})$ including the dispersion of Grimme.

\section{Results and Discussion}

\subsection{Capsules Synthesis and Optic Analysis}

Figure 1a - and b- show optical microscopy images of the spheres after 2 hours of crosslinking with Fe (III). It can be seen a light brown-orange central structure with transparent extensions (ramifications) of the biopolymer. This indicates that this capsule is very poorly consolidated in the external part with greater presence of Fe (III) inside it. This phenomenon of branching explains the structural weakness of this capsule.

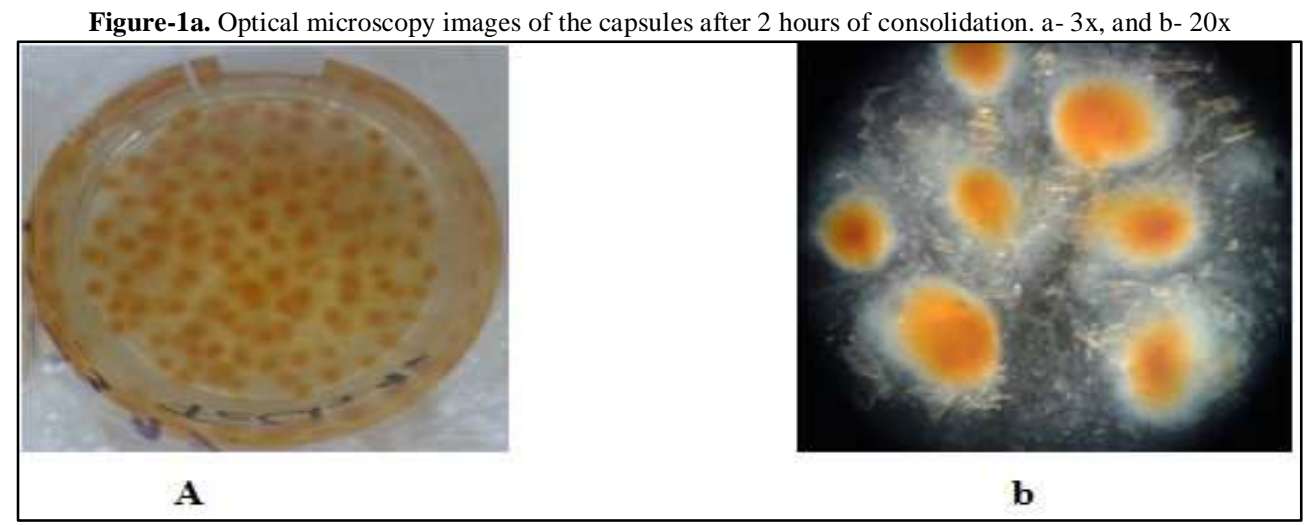

Figure-2a. Optical microscopy images of the capsules after 24 hours of consolidation. a- 3x, and b- 20x

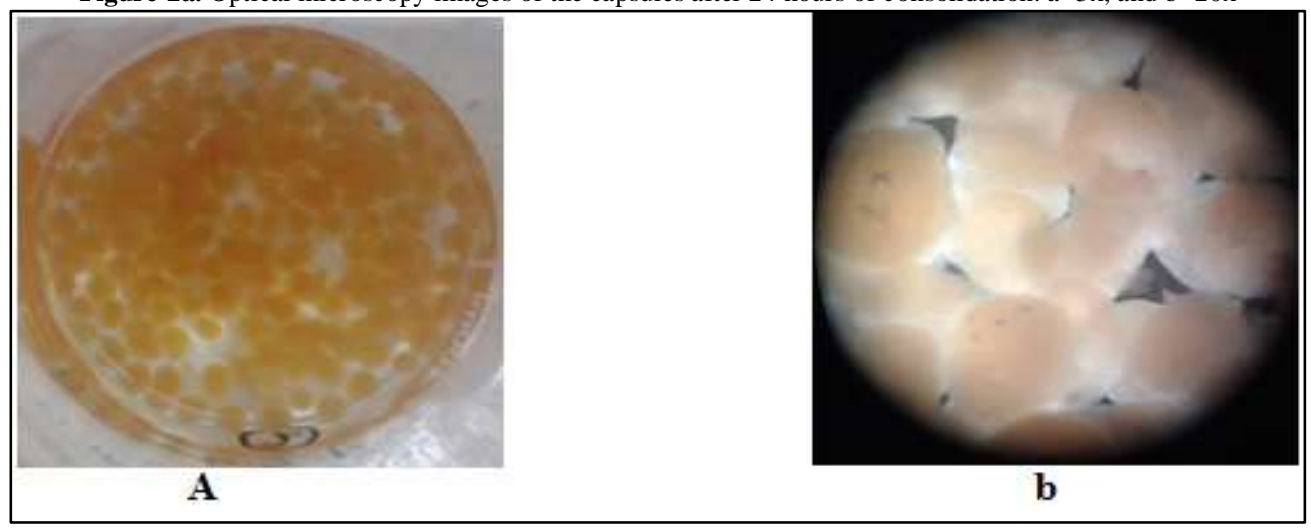


Figure 2a- and b- show the capsules 24 hours after the synthesis. They present a greater consolidation and stability, the external transparent structure is not observed, but a capsule of more homogeneous shape and better consolidated. They size of approximately $0.5 \times 0.4 \mathrm{~mm}$ is uniform.

\subsection{SEM-EDX}

In order to know the surface morphology of the obtained films, SEM images of Xan and Xan-Fe capsules were obtained. In Xan film a smooth and dense surface is observed with some particles protruding on the surface (Figure 3). The crosslinked capsules lose this superficial softness and a much rougher surface is observed due to the appearance of new bonds between the molecules by the crosslinking agent.

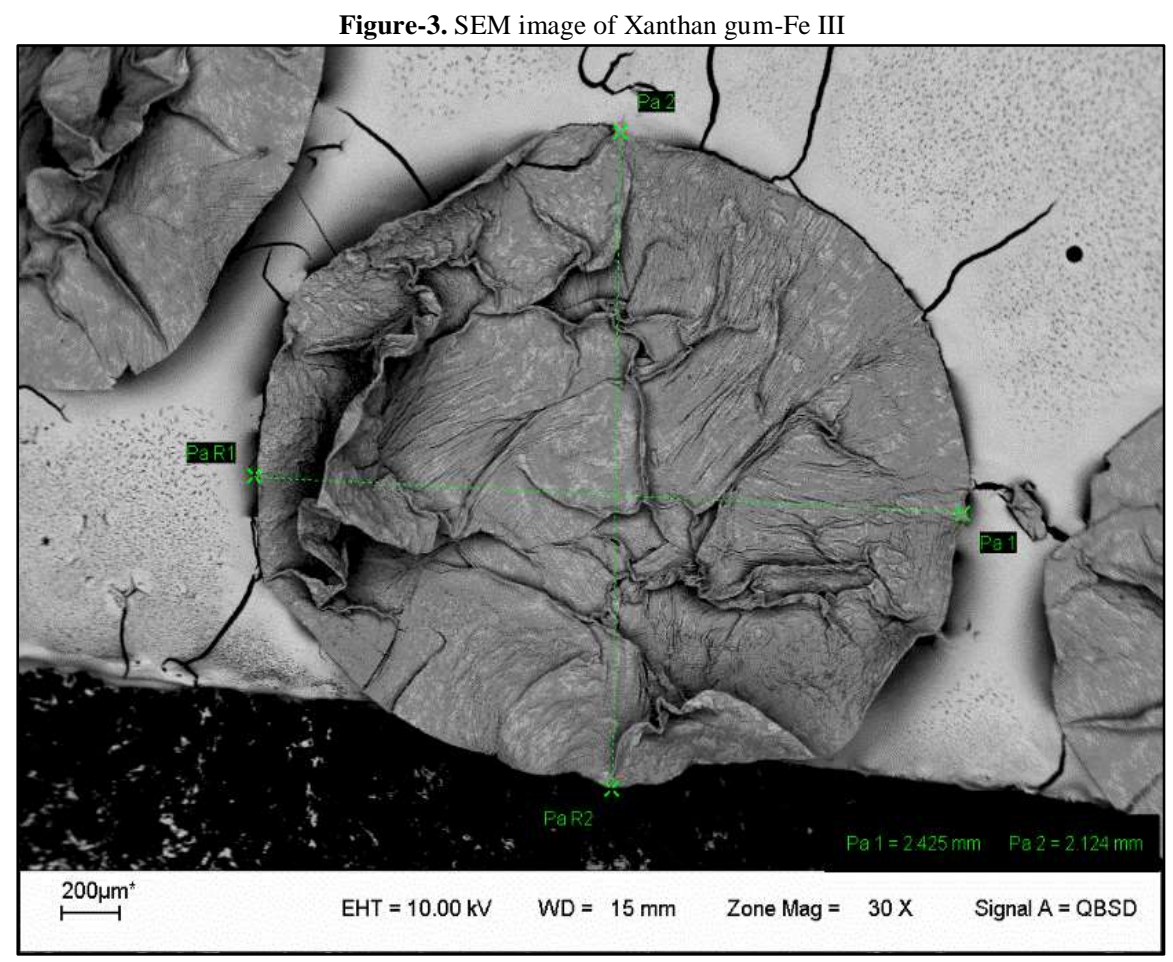

The SEM images were taken to $30 \mathrm{X}$ of dehydrated capsules these were spheroid form, with a size of $2.425 \mathrm{x}$ $2.124 \mathrm{~mm}$. It can be also observed that the capsule once dehydrated collapses generating a very rough structure with sheets, due to the loss of water, see Figure 3.

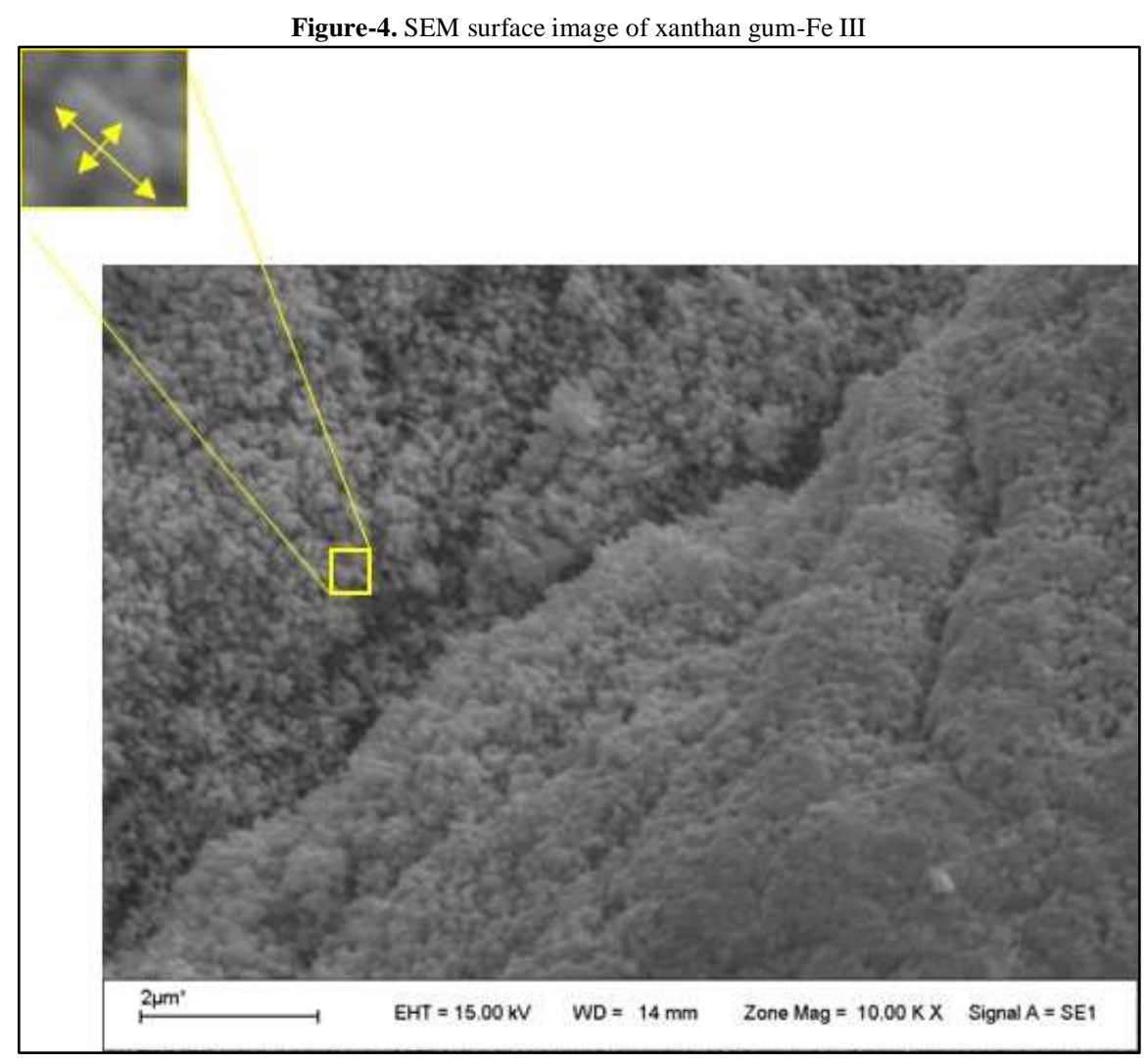


Figure-5. SEM image and EDX chromatograms of samples

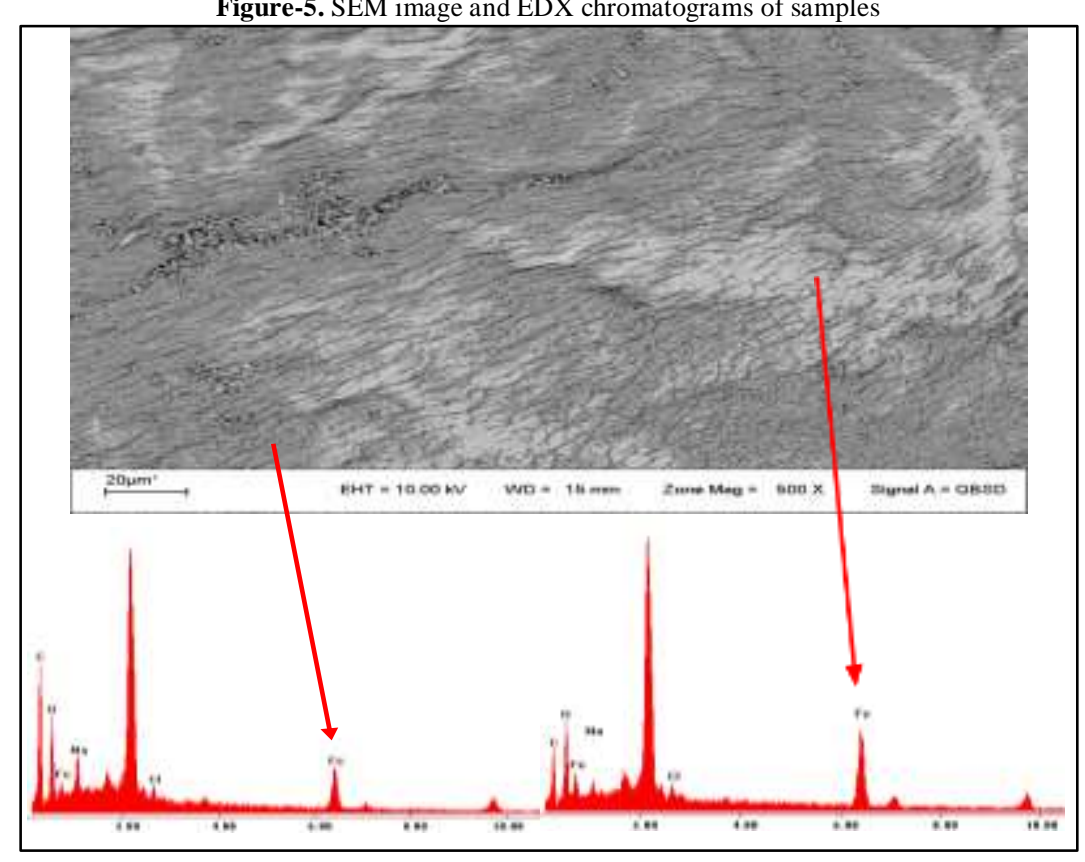

Comparing Figure 4 and 5, it is observed that the image of the film Xan-Fe film presents less roughness than the Xan because the large number of bonds formed in the longer crosslinking, generate a very dense network of polysaccharides that consolidates the surface.

The SEM images were taken to $10000 \mathrm{X}$ of dehydrated capsules to observe the nanoparticles in the matrix, these were rod-like form, with a size of $0.25 \times 0.08 \mu \mathrm{m}$ approximately (see Figure 4 ). These particles are packed neatly and by zones, with some of them disordered. This type of structure can be the one that explains its collapse when dehydrated. These macroparticles are packed neatly and by zones, with some of them disordered. This type of microstructure may be the one that explains its collapse when dehydrated.

Figure 5 shows two types of backscattered coloration, which shows that there may be areas rich in Fe and another poorer, this can demonstrate the lack of consolidation in the microspheres when the spheroid is dehydrated.

\subsection{Ftir Spectroscopy}

The broad intense band located at $3436 \mathrm{~cm}^{-1}$ xanthan gum and $3417 \mathrm{~cm}^{-1}$ xanthan gum-Fe III was ascribed to terminal hydroxyl stretching vibration mode of the polysaccharide. Also the vibration centered at $2927 \mathrm{~cm}^{-1}$ was assigned to C-H stretching vibrational mode (Figure 6). As for the polysaccharides crosslinked with Fe(III) ions by $\mathrm{OH}$ groups, it can be observed a decrease in the $-\mathrm{OH}$ signal decreases along the increment of $\mathrm{Fe}$ (III), being a characteristic scenario of crosslinking process modulated by coordination of d-metals by $-\mathrm{OH}$ groups.

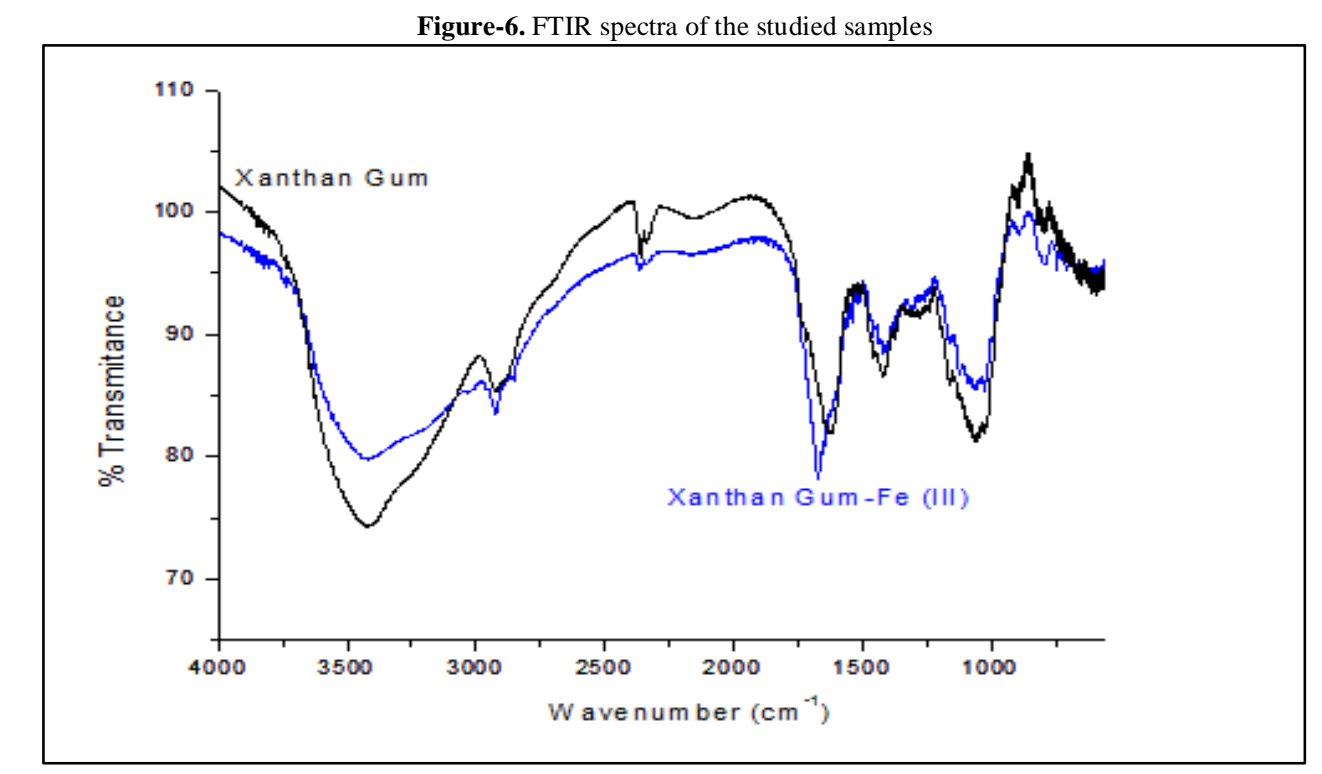

Moreover, the signals centered at $1628 \mathrm{~cm}^{-1}$ and $1418 \mathrm{~cm}^{-1}$ were assigned to the asymmetric and symmetric stretching modes of the carboxylate groups $\left(\mathrm{COO}^{-}\right)$. Also, three strong absorption bands in the range of 1200-1000 $\mathrm{cm}^{-1}$ are associated to the stretching vibrational modes of $\mathrm{C}-\mathrm{O}-\mathrm{H}$ groups, and $\mathrm{C}-\mathrm{O}-\mathrm{C}$ of the glycosidic moieties from 
pyranose rings. Finally, the signal located at $800 \mathrm{~cm}^{-1}$ is attributed to glycosidic residues (Figure 6). The shift present between $1620 \mathrm{~cm}^{-1}$ is due to the presence of Fe III attached to the caroxylate groups.

\subsection{Thermal Analysis: TGA and DSC}

Thermogravimetric (TGA) measurements were carried out in order to better assess the thermal behavior of biopolymeric capsules. The TGA demonstrates a sharp drop to around 330C for Figure 7.

Figure-7. TGA of Xanthan Gum and Xanthan Gum-Fe (III)

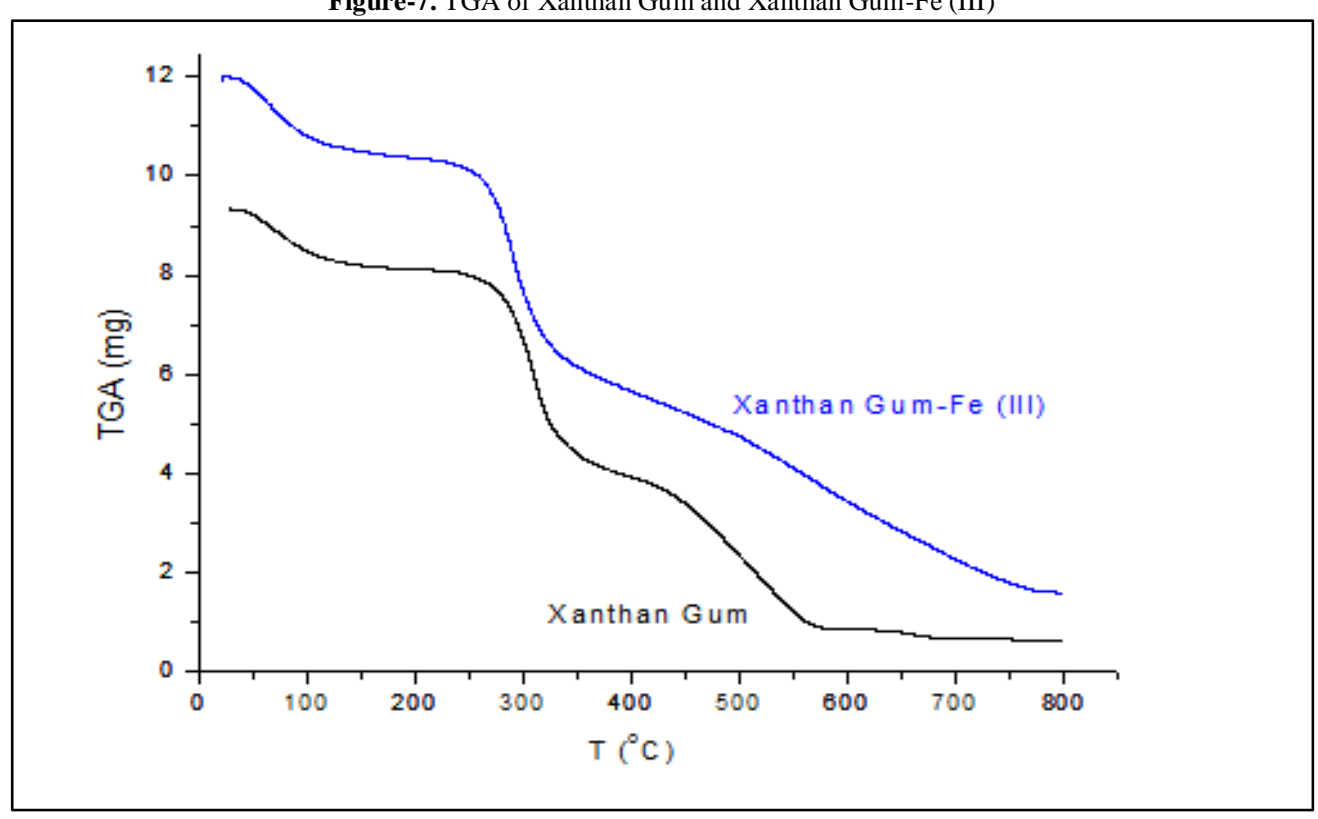

Figure-8. DSC of xanthan gum and xanthan gum-Fe III

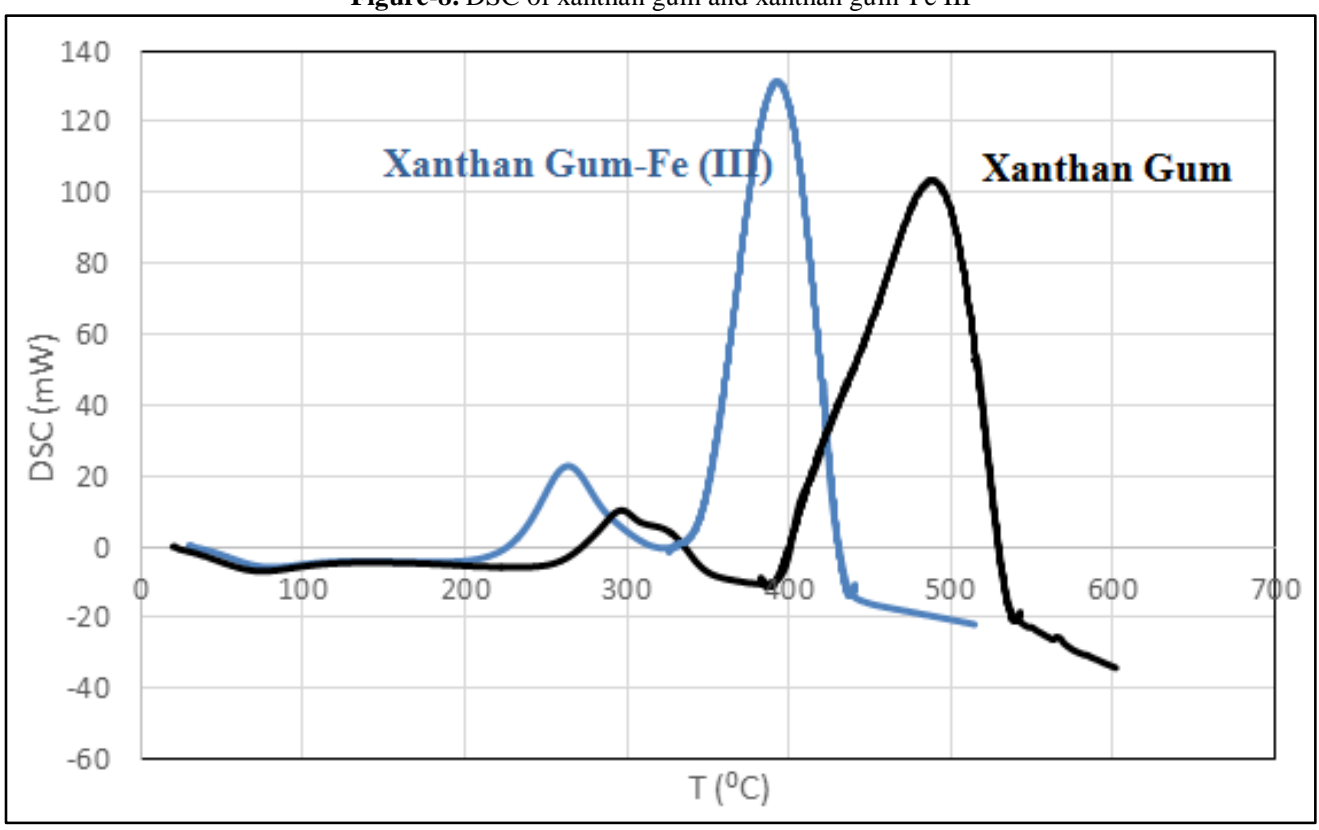

Neat xanthan gum and xanthan gum-Fe III capsules were evaluated and the corresponding results are illustrated in Figure 7. The first mass decay in both biopolymer films curves is observed close to $100{ }^{\circ} \mathrm{C}$ and it is attributed to the loss of adsorbed and structural water. This event is consistent with two endothermic DSC signals at $73.4{ }^{\circ} \mathrm{C}$ for xanthan gum and $76.75{ }^{\circ} \mathrm{C}$ for the biopolimeric metal complex (see Figure 8). Polysaccharide decomposition proceeds via two mass decays at 309 and $400{ }^{\circ} \mathrm{C}(81.25 \%)$. On the other hand, xanthan gum-Fe III capsules exhibit a different decomposition behavior; after dehydration, the second step is similar to that observed in xanthan gum but the final one appears as a continuous weight loss that extends in a major range of temperatures. During these events, $75 \%$ of mass is approximately lost, the final residue being $\mathrm{Fe}_{2} \mathrm{O}_{3}$. The DSC curves of both samples exhibit two exothermic peaks associated with the oxidation of the hydrocarbon chains.

In Figure 7 it can be seen the decomposition of both materials is carried out in three mass losses; the first two events are similar in both, while in the last one it is observed that the degradation occurs in a broader temperature range by a different process.

The DSC curves, Figure 8, show a different thermal behavior from the second stage, where the oxidation of the hydrocarbon residues occurs at a slightly lower temperature in the sample treated with Fe (III). 


\subsection{X-Ray Diffraction}

The X-Ray patterns of xanthan gum and xanthan gum-Fe III are shown in Figures 9 and 10, respectively. Even though, they evidence very low crystallinity, two very wide peaks associated to planes originated in the polymeric structure can be observed in both cases.
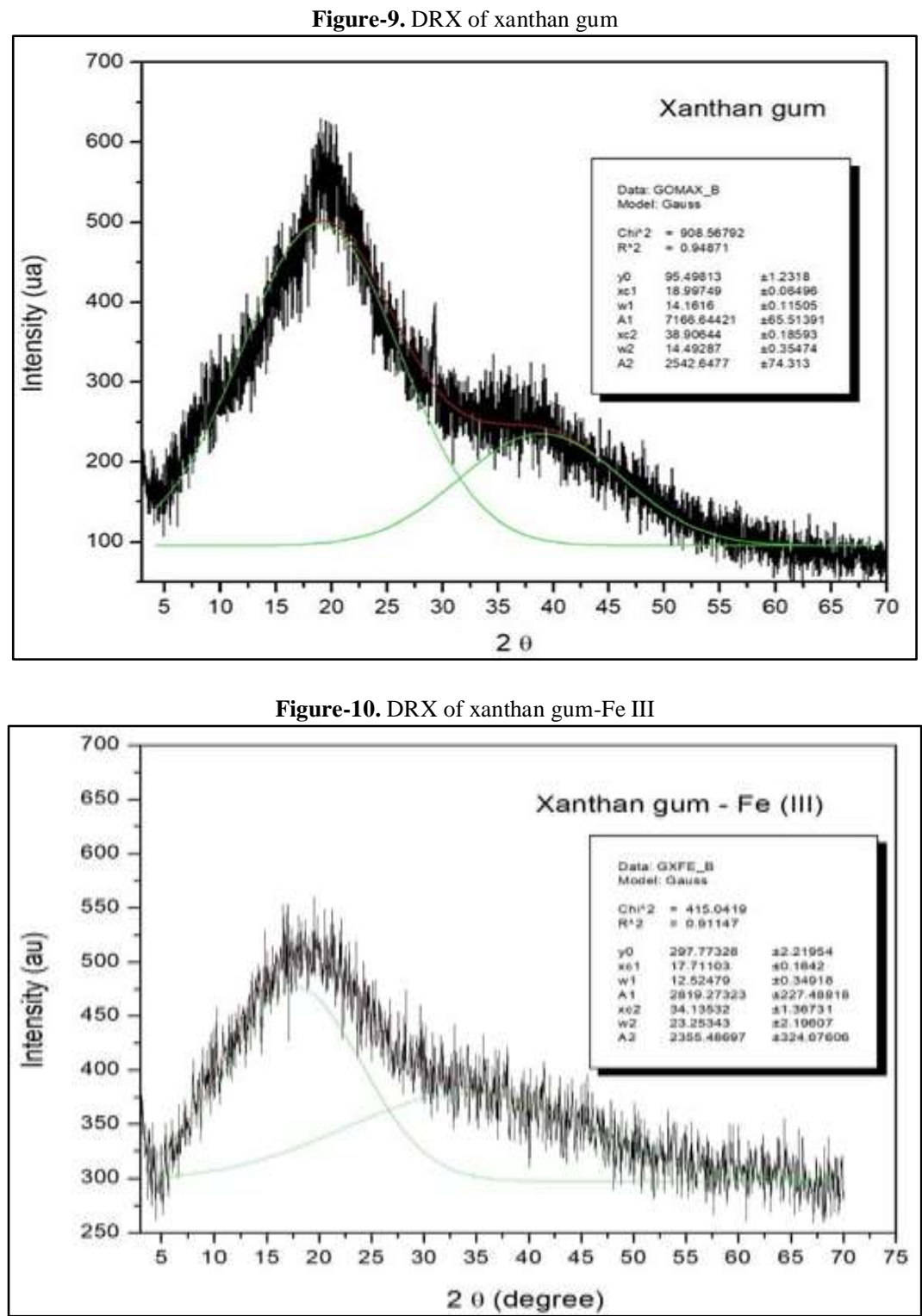

The changes in the d-spacing are attributed to metal coordination which increases the distance between the chains of the polymeric structure (from 4.67 to $5.01 \AA$ and from 2.31 to $2.63 \AA$ ) upon $\mathrm{Fe}$ (III) incorporation.

\subsection{Structure Simulation}

The DFT-D calculations allowed us to propose a coordination structure in which two glucuronic groups and two pyruvic groups coordinate coplanarly, assisted by two water molecules perpendicular to the mentioned plane. Fe(III) is in the electronic state $t_{2 g}^{3} e_{g}^{2}$ in an octahedral field, which corresponds to a state ${ }^{6} \boldsymbol{A}_{2 g}$ or pure sextuplete with $\left\langle S^{2}\right\rangle=8.75$.

A model that can fully describe the formation of the Xan-Fe capsule is the TransbiHook which would facilitate the curving of the biopolymeric structure of xanthan gum due to the presence of Fe III, a different structure is the one shown by Kang, et al. [48]. The TransbiHook model consists of a xanthan gum monomer which is linked by the pyruvate and carboxylate group with a molecule of Fe III, in turn this Fe III is linked with another xanthan gum rearranged monomer specifically with a carboxylate group and pyruvate, this scheme is reproduced at the other end of the chain, as can be seen in Figure 11. A reasonable evidence is the shifts present $1600 \mathrm{~cm}^{-1}$ in the FTIR analysis, whose intensity of xanthan gum to xanthan gum-Fe III is almost $88 \%$. 
Figure-11. Estructura propuesta en este trabajo, denominada TransbiHook

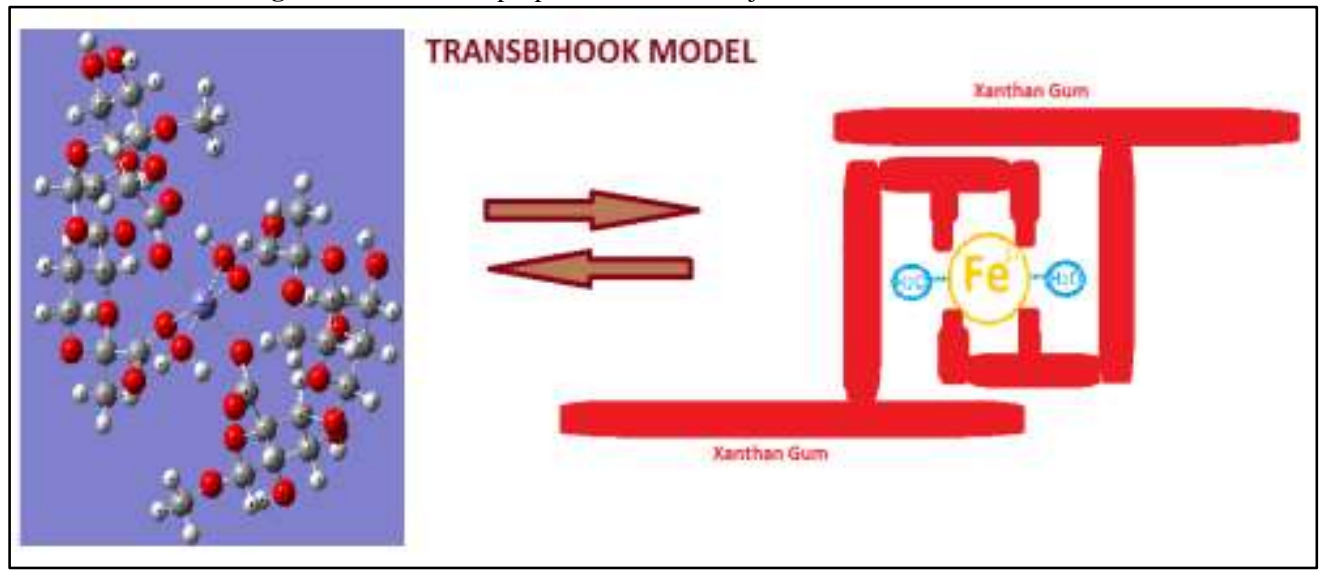

The structure shown by Kang, et al. [48], differs from that proposed by this work in that it uses two Fe III molecules linked to a pyruvate of one xanthan gum chain linked to the other transposed chain linked to a carboxylate group which is repeat with the other Faith III. This type of structure would greatly stiffen and therefore would not allow the formation of spheroids like the one carried out in this work, but it does not mean that this structure proposed by Kang, et al. [48], cannot be found. Even to clarify this situation, experimental data is lacking which corroborates this type of structure. This type of study can be extended with great caution to Al III Rodd, et al. [49] and Cr III Lund, et al. [50] and Gioia and [51].

\section{Conclusions}

The biopolymeric solutions of xanthan gum in a complexing solution of Fe III form capsules that, when dehydrated, collapse in the form of disks. These capsules have a unique characteristic in aqueous solution with many applications in the pharmaceutical and food industries. The formation of these capsules can be justified by the TransbiHook model which would justify the bending of this biopolymer complex with Fe III justified by the backscattered SEM and EDX images.

\section{Acknowledgement}

The project of the National University of San Luis, PROICO 2-2818 Dr. Martin Masuelli (INFAP-CONICET) and PROICO 2-1612 Dr. Griselda Narda (INTEQUI-CONICET).

\section{References}

[1] Kang and Pettitt, D. J., 1993. Xanthan, gellan, welan and rhamsan. In: Whistler, R. L. - bemiller j. (ed.): Industrial gums - polysaccharides and their derivations. 3rd ed. New York and London: Academy Press. pp. 341-397.

[2] Borges, C. and Vendruscolo, C., 2008. "Xanthan Gum: characteristics and operational conditions of production." Semina: Ciências Biológicas e da Saúde, vol. 29, pp. 171-188.

[3] Kranenburg, R. V., Boels, I. C., Kleerebezem, M., and Vos, W. M., 1999. "Genetics and engineering of microbial exopolysaccharides for food: approaches for the production of existing and novel polysaccharides." Current Opinion in Biotechnology, vol. 10, pp. 498-504.

[4] Tombs, M. and Harding, S., 1997. An introduction to polysaccharide biotechnology. 1st ed. London: CRC Press.

[5] Christensen, B. E. and Smidsrød, O., 1991. "Hydrolysis of xanthan in dilute acid: Effects on chemical composition, conformation, and intrinsic viscosity." Carbohydrate Research, vol. 214, pp. 55-69.

[6] Arendt, O. and Kulicke, W.-M., 1998. "Determination of the viscoelastic properties of a homologous series of the fermentation polymer xanthan gum." Die Angewandte Makromolekulare Chemie., vol. 259, pp. 6167.

[7] García-Ochoa, F., Santos, V. E., Casas, J. A., and Gómez, E., 2000. "Xanthan gum: Production, recovery, and properties." Biotechnology Advances, vol. 18, pp. 549-579.

[8] Lo, Y. M., Yang, S. T., and Min, D. B., 1997. "Effects of yeast extract and glucose on xanthan production and cell growth in batch culture of Xanthomonas campestris." Applied Microbiology and Biotechnology, vol. 47, pp. 689-694.

[9] Benny, I. S., Gunasekar, V., and Ponnusami, V., 2014. "Review on application of xanthan gum in drug delivery." International Journal PharmTech, Research, vol. 6, pp. 1322-1326.

[10] Faria, S., De Oliveira, P. C. L., and De Morais, S. A. L., 2011. "Characterization of xanthan gum produced from sugar cane broth." Carbohydrate Polymers, vol. 86, pp. 469-476.

[11] Bueno, V. B. and Petri, D. F. S., 2014. "Xanthan hydrogel films: Molecular conformation, charge density and protein carriers." Carbohydrate Polymers, vol. 101, pp. 897-904. 
[12] Leela, J. K. and Sharma, G., 2000. "Studies on xanthan production from Xanthomonas campestris." Bioprocess Engineering., vol. 23, pp. 687-689.

[13] García-Ochoa, F., Santos, V. E., Casas, J. A., and Gómez, E., 2000. "Xanthan gum: production, recovery, and properties." Biotechnology Advances, vol. 18, pp. 549-579.

[14] Casas, J. A., Santos, V. E., and Garcia-Ochoa, F., 2000. "Xanthan gum production under several operational conditions: molecular structure and rheological properties." Enzyme and Microbial Technology, vol. 26, pp. 282-291.

[15] Fernandes, S., Marceli, R. C. G., Fornari, M. A., Mazutti, D. d. O., Francine, F. P., Alexandre, J. C., Rogério, L. C., and Marco, D. L., 2009. "Helen Treichel Production and characterization of xantham gum by Xanthomonas campestris using cheese whey as sole carbon source." Journal of Food Engineering, vol. 90, pp. 119-123.

[16] Kalogiannis, S., Gesthimani, I., Maria, L.-K., Dimitrios, A. K., and George, N. S., 2003. "Optimization of xanthan gum production by Xanthomonas campestris grown in molasses." Process Biochemistry, vol. 39, pp. $249-256$

[17] Psomas, S. K., Liakopoulou-Kyriakides, M., and Kyriakidis, D. A., 2007. "Optimization study of xanthan gum production using response surface methodology." Biochemical Engineering Journal, vol. 35, pp. 273280.

[18] Sharma, B. R., Naresh, L., Dhuldhoya, N. C., Merchant, S. U., and C., M. U., 2006. "Xanthan gum - a boon to food industry." Food Promotion Chronicle, vol. 1, pp. 27-30.

[19] Bezemer, L., Job, B., Ubbink, J. A., de Kooker, M. E., and Kuil, J. C. L., 1993. "On the conformational transitions of native xanthan." Macromolecules, vol. 26, pp. 6436-6446.

[20] Holzwarth, G., 1978. "Molecular weight of xanthan polysaccharide." Carbohydrate Research, vol. 66, pp. 173-186.

[21] Rinaudo, M. and Milas, M., 1982. "Xanthan properties in aqueous solution." Carbohydrate Polymers, vol. 2, pp. 264-269.

[22] Kudaibergenov, S. E., 1999. "Recent advances in the study of synthetic polyampholytes in solutions." Advances in Polymer Science, vol. 144, pp. 115-197.

[23] Petri, D. F. S., 2015. "Xanthan Gum: A versatile biopolymer for biomedical and technological applications." J. Appl. Polym. Sci., Available: https://onlinelibrary.wiley.com/doi/full/10.1002/app.42035

[24] Sanderson, G. R., 1981. "Applications of xanthan gum." British Polymer Journal, vol. 13, pp. 71-75.

[25] Grant, G. T., Edwin, R., Morris, D. A., Rees, P., Smithe, J. C., and David, T., 1973. "Biological interactions between polysaccharides and divalent cations: The egg-box model." FEBS Letters, vol. 32, p. 1.

[26] Zhiming, G., Yapeng, F., Yiping, C., Hua, L., Katsuyoshi, N., and Glyn, O. P., 2017. "Hydrocolloid-food component interactions." Food Hydrocolloids, vol. 68, pp. 149-156.

[27] Davarc1, F., Deniz, T., Beraat, O., and Denis, P., 2017. "The influence of solution viscosities and surface tension on calcium alginate microbead formation using dripping technique." Food Hydrocolloids, vol. 62, pp. 119-127.

[28] Patel, M. A., Mohamed, H. H., Abou, G., Jacqueline, V., and Schryer-Praga, K. C., 2017. "The effect of ionotropic gelation residence time on alginate cross-linking and properties." Carbohydrate Polymers, vol. 155, pp. 362-371.

[29] Zheng, H., Gao, M., Ren, Y., Lou, R., and Xie, H., 2017. "An improved pH responsive carrier based on EDTA-Ca-alginate for oral delivery of Lactobacillus rhamnosus ATCC 53103. ." Carbohydrate Polymers, vol. 155, pp. 329-335.

[30] Bourgeois, S., Gernet, M., Pradeau, D., Andremont, A., and Fattal, E., 2006. "Evaluation of critical formulation parameters influencing the bioactivity of [beta]-lactamases entrapped in pectin beads." International Journal of Pharmaceutics, vol. 324, pp. 2-9.

[31] Ghibaudo, F., Esteban, G., Viviana, C., and Dall' Orto, 2017. "Andrea Gómez-Zavaglia. Pectin-iron capsules: Novel system to stabilize and deliver lactic acid bacteria." Journal of Functional Foods, vol. 39, pp. 299-305.

[32] Chatterjee, S., Hai Nguyen, T., Ohemeng-Boahen, G., and Seung, H. W., 2018. "Supersorption capacity of anionic dye by newer chitosan hydrogel capsules via green surfactant exchange method." ACS Sustainable Chem. Eng., vol. 6, p. 3604-3614.

[33] Shang, C., Yanjun, C., Chaocan, Z., Zongyi, D., and Zhihui, W., 2017. "Destruction of chitosan capsules based on host-guest interaction and controllable release of encapsulated dyes." J. Appl. Polym. Sci., Available: https://onlinelibrary.wiley.com/doi/abs/10.1002/app.45229

[34] Suppharada, J., Chaleeda, B., and Romanee, S., 2017. "Microencapsulation of probiotic and prebiotic in alginate-chitosan capsules and its effect on viability under heat process in shrimp feeding." Materials Today: Proceedings, vol. 4, pp. 6166-6172.

[35] Varankovich, N., Martinez, M. F., and Nickerson, M. T., 2017. "Survival of probiotics in pea proteinalginate microcapsules with or without chitosan coating during storage and in a simulated gastrointestinal environment." Food Sci. Biotechnol., vol. 26, p. 189.

[36] Bandwar, R. and Rao, C., 1996. "Transition-metal-saccharide chemistry: synthesis and characterisation of D-galactose, D-fructose, D-glucose, D-xylose, D-ribose and maltose complexes of Mn(II)." Carbohydrate Research, vol. 287, pp. 157-168. 
[37] Gyurcsik, B. and Nagay, L., 2000. "Carbohydrates as ligands: coordination equilibria and structure of metal complexes." Coord. Cem. Rev., vol. 203, pp. 81-149.

[38] Ciesielski, W., Kozioł, J. J., and Tomasik, P., 2003. "Complexes of amaranthus starch with selected metal salts and their thermolysis." Thermochim. Acta., vol. 403, pp. 161-171.

[39] Ciesielski, W. and Tomasik, P., 2003. "Coordination of cassava starch to metal ions and thermolysis of resulting complexes." Bull. Chem. Soc. Ethiopia., vol. 17, pp. 155-165.

[40] Ciesielski, W. and Tomasik, P., 2004b. "Werner-type metal complexes of potato starch." Int. J. Food Sci. Tech., vol. 39, pp. 691-698.

[41] Ciesielski, W., Tomasik, P., Lii, C. Y., and Yen, M. T., 2003. "Interactions of starch with salts of metals from the transition groups." Carbohydr. Polym., vol. 51, pp. 47-56.

[42] Ciesielski, W. and Tomasik, P., 2004a. "Complexes of amylose and amylopectins with transition metal salts and their thermal properties." J. Inorg. Biochem., vol. 98, pp. 2039-2051.

[43] Saalwächter, K., Burchard, W., Klüfers, P., Kettenbach, G., Mayer, P., Klemm, D., and Dugarmaa, S., 2000. "Cellulose solutions in water containing metal complexes." Macromolecules, vol. 33, pp. 4094-4107.

[44] Ciesielski, W., 2004a. "Complexes of anionic polysaccharides with metal salts. Part II: Kappa carrageenan." J. Food, Agr. Environ., vol. 2, pp. 17-25.

[45] Ciesielski, W., 2004b. "Complexes of anionic polysaccharides with metal salts. Part III: Iota carrageenan." J. Food, Agr. Environ., vol. 2, pp. 26-32.

[46] Ciesielski, W., 2004c. "Complexes of anionic polysaccharides with metal salts. Part IV: Lambda carrageenan." J. Food, Agr. Environ., vol. 2, pp. 33-39.

[47] Vega, E. D., Elena, V., Jorge, R. A., and Diaz, M. A., 2015. "Masuelli." Journal of Polymer and Biopolymer Physics Chemistry, vol. 3, pp. 12-18.

[48] Kang, Olayinka, O., Shunli, L., Qianqian, H., Wenjing, M., Fang, Y., and Guodong, F., 2019. "Characterization of Xanthan gum-based hydrogel with Fe3+ ions coordination and its reversible sol-gel conversion." Carbohydrate Polymers, vol. 203, pp. 139-147.

[49] Rodd, A. B., Dave, E., Dunstan, D. V., Boger, J. S., and Walther, B., 2001. "Heterodyne and nonergodic approach to dynamic light scattering of polymer gels: Aqueous xanthan in the presence of metal ions (aluminum(iii))." Macromolecules, vol. 34, pp. 3339-3352.

[50] Lund, T., Olav, S., Bjorn, T. S., and Arnljot, E., 1988. "Controlled gelation of xanthan by trivalent chromic ions." Carbohydrate Polymers, vol. 8, pp. 245-256.

[51] Gioia, F. and , U. M., 2004. "The containment of oil spills in unconsolidated granular porous media using xanthan/Cr(III) and xanthan/Al(III) gels." Journal of Hazardous Materials, vol. 116, pp. 83-93. 